INTERNATIONAL DESIGN CONFERENCE - DESIGN 2018

https://doi.org/10.21278/idc.2018.0424

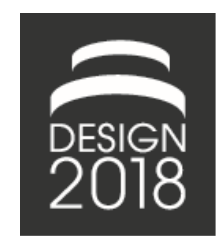

\title{
MODELLING THE RELATIONSHIP BETWEEN DESIGN ACTIVITY AND COMPUTER-SUPPORTED COLLABORATIVE DESIGN FACTORS
}

\author{
R. Brisco, R. I. Whitfield and H. Grierson
}

\begin{abstract}
Computer-Supported Collaborative Design (CSCD) technologies can enable teams to collaborate across boundaries. Emerging research documents the potential of CSCD technologies to contribute towards successful collaborative design, however, no model exists to define the relationship between a successful design activity and CSCD factors which influence its success. This paper utilises a systematic literature review to categorise known CSCD factors, categorise and characterise them, and applies this knowledge towards developing an established design activity model to include CSCD factors.
\end{abstract}

Keywords: collaborative design, modelling, product design, engineering design, CSCD

\section{Introduction}

In the past, products were typically developed by a small team in a collocated space. Now, global teams have the challenge of distributed working and new collaborative challenges have emerged. Using Computer-Supported Collaborative Design (CSCD) technologies, engineering design teams utilise design activities to progress the development of a product. Communication technologies can facilitate discussion, sharing functionalities can enable data transfer and polling mechanisms can enable democratic decision making. The inclusion of CSCD technologies in the design process has changed how knowledge and resources are used to facilitate design activities (Shen et al., 2015). A better understanding and definition of the CSCD factors which influence design activities will enable the investigation of more efficient engineering design team work. This research presents the development of a design activity model to define how CSCD factors influence successful design activities.

CSCD is an area of research investigating how computer technology can influence the design process to support collaboration. These might include common tools such as email and video conference, function specific software such as social software and digital whiteboards or highly specialised functional tools such as CAVE environments and knowledge management systems. These technologies and more enable collaborative design to take place on a digital device. Emerging research suggests that using specific technologies at specific times of the design process can advance or delay the progress of the design project and that certain technologies might be more efficient than others (Mamo et al., 2015). There has been research in the field of CSCD to investigate how individual CSCD factors impact the activities of the engineering design teams (Borsato and Peruzzini, 2015; Shen et al., 2015). However, with such a varied area of study spanning disciplines of design research, Computer-Supported Cooperative Work (CSCW), human-computer interaction, computer science and engineering, there has been no co-ordinated approach to attempt to pull together the full extent of the influence of the CSCD factors on a design activity. The development of a design activity model to consider CSCD factors has the capability to bring published research together, categorise, characterise, and identify gaps in the 
knowledge towards a more co-ordinated approach. The E2 design activity model was identified as a way of presenting the CSCD factors which influence design activities and explore their influence.

At a rudimentary level, collaboration is working with someone to produce something and co-ordination is the management of this process. Within design, it is important to co-ordinate the resources and contribute to activities with others to facilitate a change in knowledge. If collaboration is successfully supported, companies can have the global capabilities to remain competitive and employ agility in their design process to respond to opportunities (Khalil et al., 2013). Duffy (2002) first proposed the E2 design activity model (Figure 1) which characterises the change in knowledge during a design activity based on a design co-ordination framework. The model is in the notation of Integrated Definition Language IDEF-0 where the design activity has three inputs and leads to one output. Input knowledge is converted into output knowledge through a design activity. The ability of the design activity to convert this knowledge is affected by resources availability towards a goal. Input knowledge can originate from previous design activities or the knowledge held by the participants to the design activity. Resources can be knowledge based, action based, or artefact based contributing to the facilitation of the design activity. The E2 design activity model was identified for this research task as it can be used to represent effectiveness and efficiency based on the success of the design activity. The effectiveness of a design activity is characterised as how well the output meets the goal of the design activity. The efficiency of a design activity is characterised as how well the input knowledge has been transformed into output knowledge with the use of resources. These are calculated mathematically as detailed by Boyle et al. (2009). The E2 design activity model was developed based on factors of co-ordination. If CSCD factors could be applied to the E2 design activity model it would allow for a definition of the complexities in conducting a design activity influenced by CSCD factors, which could be applied in the development of support systems for engineering design teams.

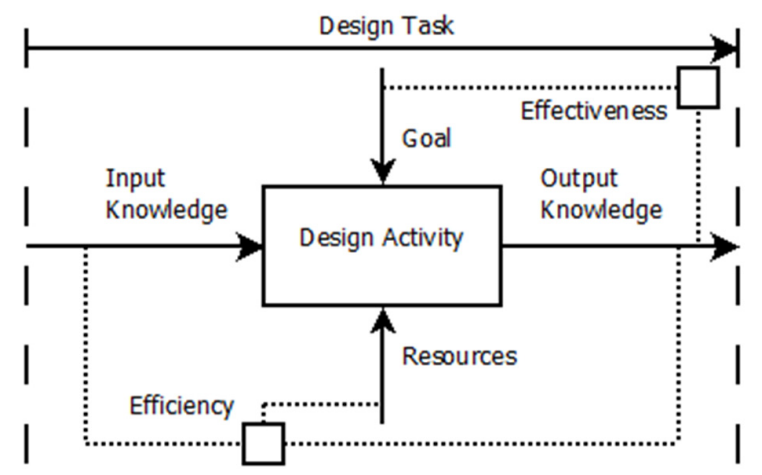

Figure 1. E2 design activity model with effectiveness and efficiency measurement (adapted from Duffy, 2002)

This research aimed to define the relationship between CSCD factors and the design activity. To achieve this, the E2 design activity model was developed to include CSCD factors. This paper details the methods used to gather CSCD factors, categorising and characterising them, and how they were used to develop model. The process of conducting this is detailed with findings on the characteristics of CSCD factors. The potential of the model is discussed including the next steps for this research project.

\section{Methodology}

To establish the relationship between CSCD technology and design activity, three research activities were identified: a systematic literature review to gather CSCD factors, a categorisation activity to refine the list of CSCD factors, to characterise the CSCD factors, and a modelling activity to understand the relationship between the CSCD factors and a design activity. These activities were selected to utilise the full range of CSCD knowledge currently available from academic literature including research into new CSCD technologies, studies into human-computer interaction, exploratory studies of student experiences in CSCD projects and case studies from industries adoption of CSCD technology. 


\subsection{Systematic literature review - gathering the CSCD factors}

As the field of CSCD relates to multiple disciplines, an interdisciplinary research approach was required, and a systematic literature review enabled this. The systematic literature review process is represented in Figure 2.

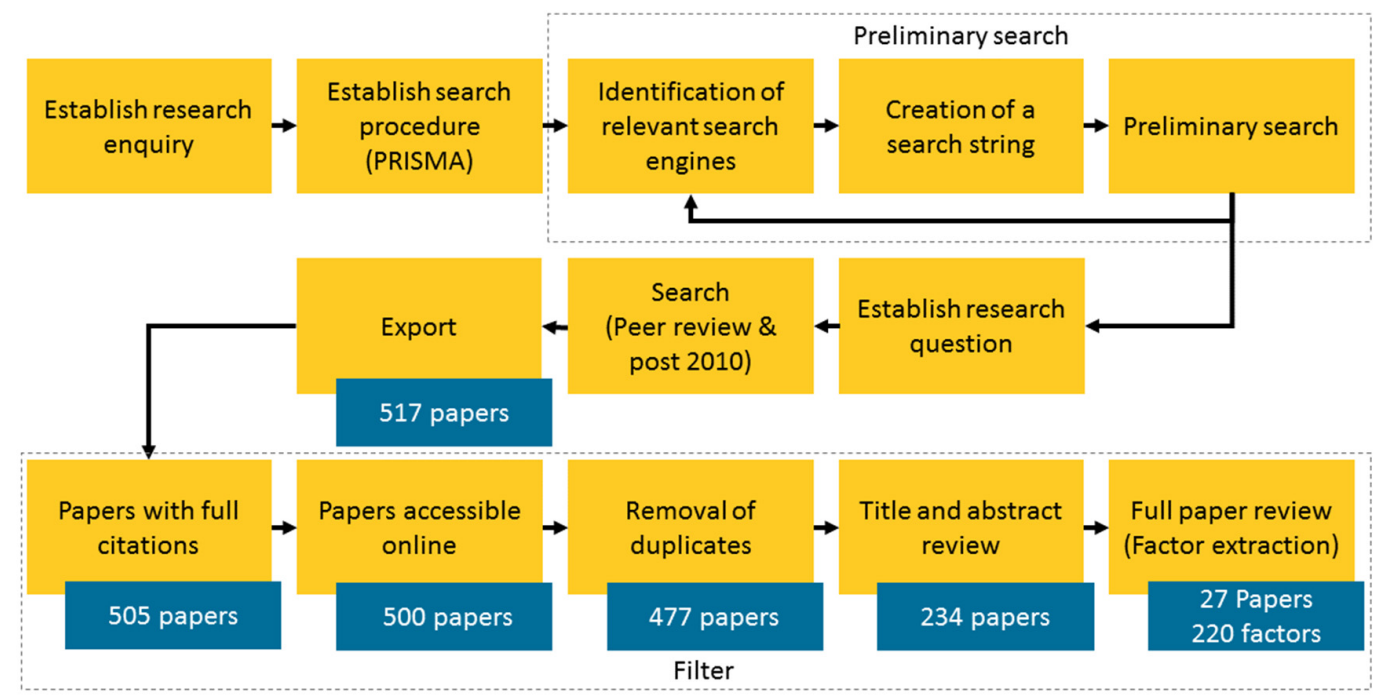

Figure 2. Systematic literature review process

The focus of the systematic literature review was to gather the CSCD factors which influence the design activities of engineering design teams as identified in academic papers, journals and books. A preliminary search was conducted to iteratively build a list of relevant academic search engines and the creation of a search string (Table 1) to consider all papers. Search engines were selected as they index the fields of engineering, technology, computer science and education. In total, six search engines were selected from a list of hundreds available to the author. These are Proquest, Engineering Village, IEEE Xplore, Scopus, EBSCO and ACM Digital Library.

Table 1. Search strategy

\begin{tabular}{|c|c|c|c|c|}
\hline Field & \multirow{9}{*}{ 安 } & Domain & \multirow{9}{*}{ 要 } & Specialist \\
\hline "Collaborative Design" & & Engineering N/1 Design & & Computer W/1 Supported \\
\hline "Design Teamwork" & & "Product Design" & & Social W/1 Network \\
\hline \multirow[t]{6}{*}{ "Cooperative Design" } & & "Industrial Design" & & Social W/1 Software \\
\hline & & "Design Studies" & & Mobile W/1 Devices \\
\hline & & & & Mobile W/1 Phone \\
\hline & & & & Smart W/1 Phone \\
\hline & & & & Tablet W/1 Computer \\
\hline & & OR & & OR \\
\hline
\end{tabular}

To identify relevant papers during the preliminary search three categories were established: field, domain and specialist. It was identified that if a paper matched one search term in each category it is considered highly relevant to the study. These categories focus the scope of the investigation, for example, a search for collaborative design AND engineering design AND computer supported would identify papers related to the goal of understanding how computers can support engineering designers to conduct collaborative design activities. Terms such as 'social network' were added to ensure the latest technologies were included in the study, this was identified as a weakness during the iterative search. 
The systematic literature review was conducted on peer-reviewed documents published between January 2010 and February 2017. Exclusions were applied to duplicated papers, non-accessible and nonEnglish papers. Any papers which report data collected before 2010 were excluded to ensure modern theories of CSCD were used. CSCD factors were extracted from papers which remained.

\subsection{Categorisation of the CSCD factors}

The CSCD factors extracted from the literature was grouped into five categories based on the context of the factor within its originating source. These categories were created iteratively by the lead author, taking inspiration from Mattessich and Monsey (1992) six categories of successful collaboration factors. This book and its simple categorisation is a landmark in this research area. Because of its age and simplicity, it may not fully represent modern CSCD but is a good starting point when considering influencing CSCD factors. During categorisation it was apparent that these six categories could not represent all factors successfully and some development was required. Communication was changed to communication channels to represent the multiple methods and forms of communication. Environment was changed to collaborative environment to fairly represent collaboration considerations and clearly exclude communication, co-operation and co-ordination factors. Membership characteristics was changed to team membership characteristics to differentiate between the core design team and extended stakeholders. Process/structure was changed to process and structure. Resources was changed to resource ability to differentiate between the availability of resources and their ability. The category of purpose was removed as none of the CSCD factors related to the purpose of initiating the collaboration.

CSCD factors were coded with categories based on the five categories. One researcher was responsible for coding the CSCD factors which was checked by two other researchers with experience in the area. Few factors were changed based on the opinions of the researcher's opinions and no conflicts between the opinions of the research was disputed. Further efforts have been made to subcategories the factors and find larger consensus before further development of the model or use of the factors. Factors were only categorised into one category based on their affordance to the engineering design team.

\subsection{Modelling the relationship}

From the categorisation of the CSCD factors, the potential for development of the model was confirmed. The next step was to investigate which parts of the E2 design activity model would be affected by a change in the CSCD factors and what type of relationship the CSCD factors might have on the model considering the inputs and the effectiveness and efficiency measurement. In developing the model, three investigations were conducted: the relationship between the CSCD factors and the components of the existing model, the influence of positive and negative CSCD factors and the influence of human and technological factors. Influence is discussed further in Section 3.2.1 as an outcome of the categorisation activity.

\section{Results}

In this section, the results of the research activities are described to give an understanding of how the model was created and to present the model itself. Three activities contributed to the development of the model and had specific outcomes: a systematic literature review which identified CSCD factors, a categorisation which identified 5 categories and further insights into the nature of the CSCD factors, and the modelling itself in the creation of the model.

\subsection{Systematic literature review - gathering the CSCD factors}

The systematic literature review revealed 517 papers which met the field, domain and specialist search terms. To be included the paper must explicitly report on the requirements, barriers or benefits of CSCD technology to support engineering design team activities. 27 papers met this criterion. A typical example of this is in Gopsill et al. (2013) where twenty requirements statements were reported 
allowing this research to benefit and build upon the statements and bring together theories from different backgrounds.

In total 220 CSCD factors were extracted. The full list of CSCD factors cannot be included in this submission because of the space required, but, all CSCD factors and categorisations can be found in detail at: http://doi.org/10.15129/a80174b4-1e48-4472-9fc2-e99738de523a.

\subsection{Categorisation of the CSCD factors}

Categorisation was used to condense the $220 \mathrm{CSCD}$ factors and to define the relationship of the factors with the design activity. Table 2 displays the categories of the CSCD factors adding a description of the categories for context.

Table 2. CSCD categories and description of the categories

\begin{tabular}{|l|l|}
\hline Category & Description \\
\hline Communication channels & $\begin{array}{l}\text { The methods for communication and data transfer including images, text, video, } \\
\text { audio etc. The methods which enable stakeholder response and social } \\
\text { communication to build professional relationships. }\end{array}$ \\
\hline Collaborative environment & $\begin{array}{l}\text { Allowing all who require access and are permitted, access to relevant } \\
\text { information. }\end{array}$ \\
\hline $\begin{array}{l}\text { Team membership } \\
\text { characteristics }\end{array}$ & $\begin{array}{l}\text { Access to the knowledge of team members to share common experiences, } \\
\text { values and knowledge to support understanding between team member. } \\
\text { Supporting a shared understanding of the project and design activities for all } \\
\text { team members involved. Encouraging motivation for a project and the building } \\
\text { of trust between team members. }\end{array}$ \\
\hline Process and structure & $\begin{array}{l}\text { Implementing systematic methods for capturing knowledge and inclusive } \\
\text { procedures and methods for decision making. }\end{array}$ \\
\hline Resource ability & $\begin{array}{l}\text { Ensuring teams members and work is managed to support the design process } \\
\text { with the required skills and knowledge. Ensuring captured knowledge are } \\
\text { effectively managed so team members are best informed. }\end{array}$ \\
\hline
\end{tabular}

CSCD technologies enable communication channels to support artefact mediated communication, feedback mechanisms and social communication. These are approaches to communicate which support the built relationships between team members. Artefact-mediated communication are highquality digital representations of physical work and ideas such as images. They offer design teams the ability to elaborate on text-based communication for enhanced communication and understanding (Vyas et al., 2010b; Vyas et al., 2013; Herrmann et al., 2013; Gopsill et al., 2013). Feedback from stakeholders is crucial to the design process including the ability to view and respond to past communication supporting reflection on work (Fruchter et al., 2010; Zheng and Feng, 2012; Gopsill et al., 2013; Shen et al., 2015). Social communication encourages team synergy, knowledge sharing and serendipitous communication by supporting networking within and outside the core design team and enabling team members to build their interpersonal and negotiation skills (Vyas et al., 2010b; Xie et al., 2010; Antunes et al., 2011; Iacob, 2011; Wangsa et al., 2011; Vyas et al., 2013; Bittner and Leimeister, 2013; Rapanta et al., 2013; Cho and Cho, 2014; Borsato and Peruzzini, 2015).

CSCD technologies take many different forms of collaborative environment including: collocated, distributed, real-world and digital environments to support access and integration into the company's design process. Technologies have the potential to overcome boundaries of access to easily view and edit files freely (Iacob, 2011; Wangsa et al., 2011; Herrmann et al., 2013; Pavković et al., 2013). Integrating collaborative technologies with standardised procedures and policies enable teams to assume clear roles and responsibilities, reduce the sense of lack of control and optimise team negotiation cycles (Xie et al., 2010; Iacob, 2011; Wangsa et al., 2011; Bittner and Leimeister, 2013; Gopsill et al., 2013; Pavković et al., 2013; Rapanta et al., 2013; Cho and Cho, 2014; Shen et al., 2015).

CSCD technologies enable consideration and support for team membership characteristics and the inter-team relationships. The barriers of physical proximity, cultural understanding, different 
languages, and different time zones can be supported with collaborative technologies and enables a greater awareness of community and environmental issues (Hirlehei and Hunger, 2011; Wangsa et al., 2011; Bittner and Leimeister, 2013; Rapanta et al., 2013). Motivation through social incentivisation, positive reinforcement, gamification and encouraging good morale can be supported by collaborative technologies to ensure long sustained interest in the project (Fruchter et al., 2010; Antunes et al., 2011; Bittner and Leimeister, 2013; Herrmann et al., 2013; Rapanta et al., 2013; van Dijk and van der Lugt, 2013; French et al., 2016). Shared understanding can be enabled by collaborative technologies through defining and framing conversations in a common context through shared pervasive environments, which make it easy to understand information, clarify meaning and reduce miscommunications (Fruchter et al., 2010; Xie et al., 2010; Antunes et al., 2011; Hirlehei and Hunger, 2011; Wangsa et al., 2011; Gopsill et al., 2013; Luck, 2013; Cho and Cho, 2014; Liu et al., 2014; Borsato and Peruzzini, 2015). Co-operation can be enabled by collaborative technologies through enabling a constant connection and increased awareness to encourage equal participation, anticipation of project needs, supporting design activities and opportunities for peer learning (Benolken et al., 2010; Vyas et al., 2010b; Xie et al., 2010; Iacob, 2011; Herrmann et al., 2013; Pavković et al., 2013; Rapanta et al., 2013; Cho and Cho, 2014; Liu et al., 2014; Borsato et al., 2015; Shen et al., 2015; French et al., 2016). Trust can be encouraged by collaborative technologies to support conflict resolution through increased accuracy and clarity of communication between team members (Xie et al., 2010; Wangsa et al., 2011; Pavković et al., 2013; Rapanta et al., 2013; French et al., 2016).

CSCD technologies must be compatible with existing process and structure restrictions of a team and/or organisation. Including mechanisms for decision making support, knowledge capture and objective focused communication. Decision making can be supported through increased opportunities to express opinions online, enabling team members to develop negotiation skills and concept ranking functionality (Fruchter et al., 2010; Iacob, 2011; Cho and Cho, 2014; Shen et al., 2015; French et al., 2016). Knowledge capture is supported through the recording of physical information, decisions and artefacts to document the decision-making process (Fruchter et al., 2010; Iacob, 2011; Hansen and Dalsgaard, 2012; Vyas et al., 2013; Gopsill et al., 2013). Productivity can be enabled by collaborative technologies through fast objective focused communication, organisation of work, reflection on completed work and a greater quantity of output to promote collaboration readiness and reduced rework time (Gericke et al., 2010; Xie et al., 2010; Hirlehei and Hunger, 2011; Wangsa et al., 2011; Hansen and Dalsgaard, 2012; Bittner and Leimeister, 2013; Gopsill et al., 2013; Herrmann et al., 2013; van Dijk and van der Lugt, 2013; Cho and Cho, 2014; Jinghua et al., 2014; Shen et al., 2015; French et al., 2016).

CSCD technologies support teamwork through widened resource ability. Through greater accessibility, co-ordination, innovative thinking, and knowledge management opportunities. Collaborative technologies can support competency through increased accessibility of team skills and experience, reduction of unnecessary information, and completeness of messages (Xie et al., 2010; Hirlehei and Hunger, 2011; Bittner and Leimeister, 2013; Gopsill et al., 2013; Cho and Cho, 2014). Co-ordination can be supported by a shared space for organisation of work and ease of communication, easy mechanisms for scheduling meetings and supporting the even distribution of work (Benolken et al., 2010; Fruchter et al., 2010; Xie et al., 2010; Iacob, 2011; Wangsa et al., 2011; Hansen and Dalsgaard, 2012; Horváth, 2012; Bittner and Leimeister, 2013; Gopsill et al., 2013; Pavković et al., 2013; Rapanta et al., 2013; Jinghua et al., 2014; Borsato and Peruzzini, 2015). Innovative thinking is supported by enabling agile systems to support exploration, creativity and quality of outputs. Knowledge management is enabled through organisation of information and communication, the ability to easily search and retrieve knowledge, and autonomy in the distribution of knowledge (Xie et al., 2010; Antunes et al., 2011; Iacob, 2011; Horváth, 2012; Gopsill et al., 2013; Pavković et al., 2013; Shen et al., 2015). Complexity in sharing data can be reduced through integration with data storage systems, reduced file compatibility issues and synchronous live document working with automated tracking and versioning to enable co-creation of documents, and Communication can be enhanced through synchronous multithreaded and multi-channel software for prompt discussion in a way which supports the context of the message (Benolken et al., 2010; Fruchter et al., 2010; Gericke et al., 2010; Vyas et al., 2010b; Vyas et 
al., 2010a; Antunes et al., 2011; Iacob, 2011; Hansen and Dalsgaard, 2012; Horváth, 2012; Vyas et al., 2013; Zheng and Feng, 2012; Bittner and Leimeister, 2013; Gopsill et al., 2013; Herrmann et al., 2013; Pavković et al., 2013; Rapanta et al., 2013; Liu et al., 2014; Borsato and Peruzzini, 2015; Shen et al., 2015; French et al., 2016).

\subsubsection{Influence of the factors}

During the categorisation process, the individual CSCD factors were coded for positive and negative influence and whether they originated from a human or technological process. It emerged that all CSCD factors have a binary influence, either positively or negatively affecting the outcomes of the design activity. For example, if a team member is motivated to take part in a design activity this can have a positive effect on the outcomes of the design activity (French et al., 2016), and vice versa for a demotivated team member.

CSCD research represents both factors of human interaction and computer interaction to facilitate collaborative design. To understand if this theory could be applied to the model the 220 CSCD factors were further categorised to understand if they derive from a human factor, a technological factor or both. Human factors are those that have been triggered by a human action, reaction or inaction. This includes for example: whether a team member is active in project work, if a team member is clear in their communication and their ability to align with the consensus of a group. A technological factor is one caused by the ability or inability of a technology which can act either as expected or unexpected, for example, if the technology enables ease of sharing it can support collaboration. If a technology does not it can hinder collaboration. Similarly, if a technology does not act in the way it is expected this might also hinder the collaboration.

Of the $220 \mathrm{CSCD}$ factors, 157 were categorised as being both human and technological factors, 19 were categorised as solely human factors and 44 were categorised as solely technological factors. Applying this logic to the development of the model, it's important to investigate how a change in the CSCD factors influence the components of the model and the design activity itself. This categorisation was conducted by one researcher and checked by two others. It is important before the findings are utilised further that a wider audience validate the categorisation.

\subsection{Modelling the relationship}

In developing the model, three investigations were conducted: the relationship between the CSCD factors and the components of the existing model, the influence of positive and negative CSCD factors and the influence of human and technological factors. Duffy (2002), Haffey (2007), and Boyle et al. (2009) stated that input knowledge is transformed into output knowledge through the process of conducting a design activity. Output knowledge, therefore, cannot be directly affected by a change in the CSCD factors. The goal represents the desired change in knowledge, this might be a need of the project or a requirement. The goal itself is not influenced by the CSCD factors as the goal remains the same regardless of the influencing factors. What remains is to explore if there is a relationship between the CSCD factors and the input knowledge or the resources.

The input knowledge is the information which exists and is transformed by conducting the design activity, also known as the project knowledge. If this knowledge cannot be accessed completely or is not transferred in full this can have an influence on the design activity. Table 3 gives examples for each category of how the CSCD factors affect the availability of input knowledge based on human and technology influences. A mixture of positive and negative examples has been given.

Resource contribute towards a change from input knowledge to output knowledge. If a team member necessary to the process is not available to contribute to this change of knowledge successful collaboration cannot be competently achieved. It is important to note that this change may occur positively or negatively. Additionally, the influence of the CSCD factors on the resources appears to be linked with whether the CSCD factor is a result of a human or technological impact. Table 4 gives examples for each category of how the CSCD factors affect the availability of input knowledge based on human and technology influences. A mixture of positive and negative examples has been given. 
Table 3. Examples of how the human and technological influence input knowledge

\begin{tabular}{|l|l|l|}
\hline Category & $\begin{array}{l}\text { Example of human influence on the } \\
\text { input knowledge }\end{array}$ & $\begin{array}{l}\text { Example of technological influence on the } \\
\text { input knowledge }\end{array}$ \\
\hline $\begin{array}{l}\text { Communication } \\
\text { channels }\end{array}$ & $\begin{array}{l}\text { If a team member does not fully } \\
\text { document their opinions and rationale it } \\
\text { may not be included in future design } \\
\text { activities. }\end{array}$ & $\begin{array}{l}\text { If a technology does not allow for the } \\
\text { documentation of opinions and rationale, such } \\
\text { as not allowing electronic reference, it may } \\
\text { not be included in future design activities. }\end{array}$ \\
\hline $\begin{array}{l}\text { Collaborative } \\
\text { environment }\end{array}$ & $\begin{array}{l}\text { If the organisational culture does not } \\
\text { encourage collaboration, team members } \\
\text { may not be aware of knowledge which } \\
\text { exist. }\end{array}$ & $\begin{array}{l}\text { If technologies do not include functionality to } \\
\text { request access to information the collaborative } \\
\text { environment is blocked and restricts } \\
\text { knowledge sharing. }\end{array}$ \\
\hline $\begin{array}{l}\text { Team } \\
\text { membership } \\
\text { characteristics }\end{array}$ & $\begin{array}{l}\text { If team members do not communicate on } \\
\text { a common understanding, they may } \\
\text { miscommunicate instructions restricting } \\
\text { the availability of input knowledge. }\end{array}$ & $\begin{array}{l}\text { If technologies do not make team members } \\
\text { aware of each other's work, they might not be } \\
\text { up to date with the latest knowledge available } \\
\text { to complete design activities. }\end{array}$ \\
\hline $\begin{array}{l}\text { Process and } \\
\text { structure }\end{array}$ & $\begin{array}{l}\text { If the team uses knowledge capture } \\
\text { procedures to successfully capture } \\
\text { rationale, the team can reuse this } \\
\text { knowledge in design activities. }\end{array}$ & $\begin{array}{l}\text { If knowledge capture technologies are } \\
\text { unavailable to a team, all available knowledge } \\
\text { may not be utilised by the team during design } \\
\text { activities. }\end{array}$ \\
\hline $\begin{array}{l}\text { Resource } \\
\text { ability }\end{array}$ & $\begin{array}{l}\text { If team members manage information in a } \\
\text { sensible way they will be able to search } \\
\text { and find the required knowledge for } \\
\text { design activities. }\end{array}$ & $\begin{array}{l}\text { If synchronous document editing technologies } \\
\text { are utilised, the team will have the latest } \\
\text { knowledge to include in design activities. }\end{array}$ \\
\hline
\end{tabular}

Table 4. Examples of how the human and technological influence resources

\begin{tabular}{|l|l|l|}
\hline Category & $\begin{array}{l}\text { Example of human influence on the } \\
\text { resources }\end{array}$ & $\begin{array}{l}\text { Example of technological influence on } \\
\text { the resources }\end{array}$ \\
\hline $\begin{array}{l}\text { Communication } \\
\text { channels }\end{array}$ & $\begin{array}{l}\text { Greater social communication can lead to } \\
\text { networking allowing for a greater number of } \\
\text { resources to be involved in the design } \\
\text { process. }\end{array}$ & $\begin{array}{l}\text { A feedback mechanism can allow for } \\
\text { stakeholder feedback to provoke } \\
\text { reflection. }\end{array}$ \\
\hline $\begin{array}{l}\text { Collaborative } \\
\text { environment }\end{array}$ & $\begin{array}{l}\text { Having the freedom to collaborate with } \\
\text { whoever is required for a project allows for } \\
\text { an increased resource of skills. }\end{array}$ & $\begin{array}{l}\text { Technology can enable access to resources } \\
\text { through online collaborative environments } \\
\text { whenever required to support a design } \\
\text { activity. }\end{array}$ \\
\hline $\begin{array}{l}\text { Team } \\
\text { membership } \\
\text { characteristics }\end{array}$ & $\begin{array}{l}\text { Cultural barriers can reduce awareness of } \\
\text { global issues which may not allow a team to } \\
\text { identify a local solution during design } \\
\text { activities. }\end{array}$ & $\begin{array}{l}\text { If technology does not support the } \\
\text { contextualisation of a design solution, a } \\
\text { team member may not fully understand the } \\
\text { information presented to them. }\end{array}$ \\
\hline $\begin{array}{l}\text { Process and } \\
\text { structure }\end{array}$ & $\begin{array}{l}\text { If teams do not employ opportunities to } \\
\text { share opinions and make decisions, team } \\
\text { members may not be able to utilise } \\
\text { information in design activities. }\end{array}$ & $\begin{array}{l}\text { If teams do not have access to } \\
\text { functionality which allows them to } \\
\text { systematically share their opinions, such as } \\
\text { a voting mechanism, the results of the } \\
\text { team's opinions may not be fully taken into } \\
\text { consideration during design activities. }\end{array}$ \\
\hline Resource ability & $\begin{array}{l}\text { Team members who are supported through } \\
\text { technology to explore a range of solutions } \\
\text { can build a greater knowledge of how a } \\
\text { problem can be solved }\end{array}$ & $\begin{array}{l}\text { Data storage technology which is easy to } \\
\text { access, and reflection enables teams to } \\
\text { utilise past knowledge in design activities. }\end{array}$ \\
\hline
\end{tabular}

This new knowledge on how the CSCD factors influence the resources and input knowledge was then applied to the E2 design activity model. In Figure 3, the five CSCD factor categories (on the left) generated as part of the mapping activity are visually represented impacting the resources and the input knowledge. Input knowledge and resources remain the same as the inputs to the original model. It is 
important to note that the CSCD factors do not directly affect the activity, goal or the output knowledge as discussed previously in this section.

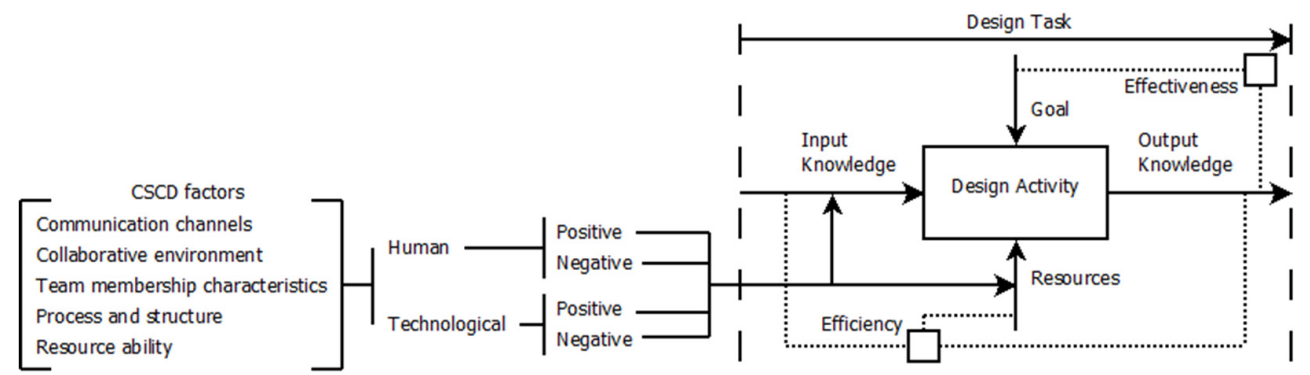

Figure 3. E2 design activity model with CSCD factors and their effect on effectiveness and efficiency

The CSCD factors which influence the availability of resources and input knowledge are shown to also have an impact on the efficiency of the design activity, but, as the goal is not affected, the effectiveness of the design activity is not influenced by CSCD factors. As discussed before, the CSCD factors can positively and negatively impact the resources available which could, in turn, affect the efficiency of the design activity. For example, if social communication is not supported, then awareness can be restricted, and the correct team members may not be included in the design activity which affects the resources available. This can extend the time required to conduct the design activity and reduce the efficiency of the design activity. If CSCD technologies do not allow easy access to documents, then the resources available to the design team during the design activity will be affected. This can result in knowledge not being available to the team, increasing rework affecting the efficiency of the design activity. To summarise the full model, CSCD factors can affect the input knowledge or the resources of the design activity. CSCD factors can be human or technological in nature, and the efficiency of the design activity is affected positively or negatively depending on the nature of the factor.

\section{Discussion}

The developed model defines the way in which CSCD factors influence design activity. The identification that the resources and input knowledge are affected make it possible to study the positive and negative effects of the factors within a CSCD context. This becomes significant when the model itself can be utilised practically to understand enablers and barriers to engineering design teamwork.

As identified in the model, the positive or negative effect of the CSCD factors can be used to understand and improve the efficiency of design activities. Ensuring that the required resources and input knowledge are available contributes towards a successful design activity. Improving efficiency is an important consideration to drive industry as identified in processes of: BIM (Shen et al., 2015), PLM (Doumit et al., 2015), PDM (Chu and Chan, 2013), and CSCD (Li et al., 2011).

Improving efficiency becomes practically useful for managers when the knowledge of the model is reversed to enable the identification of CSCD factors from efficiency problems. Having the knowledge enables an awareness of how teamwork issues, either human or technological, may be improved by turning a negative into a positive. In addition, the model has the potential to enable an efficiency measurement. If the correct resources or knowledge are not available and the required effectiveness of the design activity is not met, a decision can be made to perform the design activity with limited resources and knowledge, or methods for improving the efficiency can be implemented. This could be achieved through the development of individual metrics within the five categories.

This knowledge could be developed into software to allow design managers and facilitators to understand the weaknesses in the efficiency of their design process with respect to the CSCD factors which would make this knowledge simple and could include rationale for improvement.

The CSCD factors exist within the parameters of this research and then the parameters of the systematic literature review. Details are listed in the methodology. However, it cannot be said that other CSCD factors exist which were not collected by the systematic literature review either because they exist outside the parameters or they have never been studied and reported in the literature. This could occur 
as a lack of research in an area or because of a lack of co-ordinated approach across disciplines. Further development of the categorisation system could enable an identification of the gaps in the current knowledge for further research. This has the potential to suggest new collaborations between researchers, institutions and industry.

The initial E2 design activity model was developed based on a design co-ordination framework. This research shows how the model can be utilised to display the relationship between a design activity and CSCD factors. It could be beneficial to explore how the terms of communication, co-operation, etc, might also benefit from a more detailed inclusion in the model to enable a greater understanding of all components. This section has detailed the potential of this model if it can be validated and evaluated. The next steps for this research are to facilitate this process. The list of 220 CSCD factors is impractical to utilise and need to be condensed in some way to verify them. Categorisation is one way explored in this paper, but the context of the CSCD factors has been lost. Instead, it may be possible to create statements which summarise the CSCD factors within the categories. A smaller number of CSCD factors will be more useful but only if the idea could be retained. This would require the input of experts to ensure the statements remain true to the original CSCD factors.

Evaluation of the model comes in the form of its value. If the model can be utilised to identify the human and technological CSCD factors which positively influence the design activity, the CSCD factors could be linked to the technologies themselves. By evaluating the CSCD factors against the affordances of CSCD technologies, a toolkit could be created which fully support the requirements of engineering design teams. PLM solutions require a full commitment of the company and employees to implement. Utilising a toolkit would allow managers to source and build their technological needs from a bottomup approach potentially reducing cost and becoming customised to the companies or the project's needs. If issues of collaboration arise, the theories of the model could be utilised to identify CSCD technologies which offer a solution to human and technological issues. Flexibility in the model allows for new technologies to be integrated as they are developed as needs are discovered. To support this an evaluation matrix will be developed to allow the affordances, features and functionality of CSCD technologies to be tested and evaluated. The process itself must be validated in theory and evaluated with experimentation, case studies and real world examples.

\section{Conclusions}

The E2 design activity model was developed to define the influence of CSCD factors on design activity. The CSCD factors can be human or technological and can impact the design activity positively or negatively. This new model defines how the efficiency of a design activity can be affected by CSCD factors based on their nature. This study has revealed that in the context of a design activity there are 220 individual CSCD factors which influence the success of a design activity. These can be grouped into five categories which act as a representation of the aspects of CSCD.

The results of this work can be used to understand and define how CSCD factors influence the design activity and enable the possibility to analyse design activities back to their positive or negative influence. This also enables tools to be developed to help with the analysis of design team work. This work has shown that there is potential to support the development of the E2 design activity model further to consider other factors relating to design activity and engineering design teamwork such as co-operation and communication. Our next steps are detailed to verifying, validating and evaluating the model including the development of CSCD statements, experimental verification method and evaluation matrix with the creation of a CSCD toolkit.

\section{Acknowledgement}

This work was supported by the EPSRC under Grant EP/M508159/1.

\section{References}

Antunes, P., Ferreira, A., Zurita, G. and Baloian, N. (2011), “Analyzing the support for large group collaborations using Google Maps", Proceedings of CSCWD $2011 /$ the $15^{\text {th }}$ International Conference on Computer Supported Cooperative Work in Design, Lausanne, Switzerland, June 8-10, 2011, IEEE, pp. 748-755. https://doi.org/10.1109/CSCWD.2011.5960202 
Benolken, P., Wewior, M. and Lang, U. (2010), “A virtual workspace for distributed design and engineering tasks", Proceedings of CollaborateCom 2010 / the 6th International Conference on Collaborative Computing: Networking, Applications and Worksharing, Chicago, USA, October 9-12, 2010, IEEE, pp. 1-9. https://doi.org/10.4108/icst.collaboratecom.2010.38

Bittner, E.A.C. and Leimeister, J.M. (2013), "Why Shared Understanding Matters - Engineering a Collaboration Process for Shared Understanding to Improve Collaboration Effectiveness in Heterogeneous Teams", Proceedings of HICSS 2013 / the $46^{\text {th }}$ Hawaii International Conference on System Sciences Wailea, USA, January 7-10, 2013, IEEE, pp. 106-114. https://doi.org/10.1109/HICSS.2013.608

Borsato, M. and Peruzzini, M. (2015), “Collaborative Engineering”, In: Stjepandić, J., Wognum, N. and Verhagen W.J.C. (Eds.), Concurrent Engineering in the 21st Century, Springer, Cham, pp. 165-196. https://doi.org/10.1007/978-3-319-13776-6_7

Boyle, I.M., Duffy, A.H.B., Whitfield, R.I. and Liu, S. (2009), "Towards an understanding of the impact of resources on the design process", Proceedings of ICED'09/ the $17^{\text {th }}$ International Conference on Engineering Design, Stanford, USA, August 24-27, 2009, pp. 323-334.

Cho, J.Y. and Cho, M. (2014), "Student perceptions and performance in online and offline collaboration in an interior design studio", International Journal of Technology and Design Education, Vol. 24 No. 4, pp. 473491. https://doi.org/10.1007/s10798-014-9265-0

Chu, C.-H. and Chan, Y.-H. (2013), "Optimized distribution of product model by 3D CAD streaming in networked collaborative design", Proceedings of CSCWD 2013 / the $17^{\text {th }}$ International Conference on Computer Supported Cooperative Work in Design, Whistler, Canada, June 27-29, 2013, IEEE, pp. 477-482. https://doi.org/10.1109/CSCWD.2013.6581009

Doumit, N., Fortin, C. and Huet, G. (2015), "Study of the efficiency of product development teams through combined virtual communities of practice, PLM and social media technologies", Proceedings of ICED'15/ the $20^{\text {th }}$ International Conference on Engineering Design, Vol. 10, Milan, Italy, July 27-30, 2015, The Design Society, Glasgow, pp. 71-80.

Duffy, A.H.B. (2002), "Designing design”, Proceedings of EDIProD 2002, Zielona Góra, Poland, October 10-12, 2002.

French, D.J., Stone, B., Nysetvold, T.T., Hepworth, A. and Red, W.E. (2016), "Collaborative Design Principles from Minecraft with Applications to Multi-User CAD", Journal of Computing and Information Science in Engineering, Vol. 12 No. 2, pp. 021006. https://doi.org/10.1115/1.4032667

Fruchter, R., Bosch-Sijtsema, P. and Ruohomäki, V. (2010), "Tension between perceived collocation and actual geographic distribution in project teams”, AI \& Society, Vol. 25 No. 2, pp. 183-192. https://doi.org/10.1007/s00146-009-0254-x

Gericke, L., Gumienny, R. and Meinel, C. (2010), "Message capturing as a paradigm for asynchronous digital whiteboard interaction", Proceedings of CollaborateCom $2010 /$ the $6^{\text {th }}$ International Conference on Collaborative Computing: Networking, Applications and Worksharing, Chicago, USA, October 9-12, 2010, IEEE, pp. 1-10. https://doi.org/10.4108/icst.collaboratecom.2010.51

Gopsill, J., McAlpine, H.C. and Hicks, B.J. (2013), "A Social Media framework to support Engineering Design Communication”, Advanced Engineering Informatics, Vol. 27 No. 4, pp. 580-597. https://doi.org/10.1016/j.aei.2013.07.002

Haffey, M.K. (2007), An approach, insights and methodology for performance improvement through process activity management, $\mathrm{PhD}$ thesis, University of Strathclyde Glasgow.

Hansen, N.B. and Dalsgaard, P. (2012), "The Productive Role of Material Design Artefacts in Participatory Design Events", Proceedings of NordiCHI'12 / the $7^{\text {th }}$ Nordic Conference on Human-Computer Interaction: Making Sense Through Design, Copenhagen, Denmark, October 14-17, 2012, ACM Press, New York, USA, pp. 665674. https://doi.org/10.1145/2399016.2399117

Herrmann, T., Nolte, A. and Prilla, M. (2013), “Awareness support for combining individual and collaborative process design in co-located meetings”, Computer Supported Cooperative Work (CSCW), Vol. 22 No. 2-3, pp. 241-270. https://doi.org/10.1007/s10606-012-9179-X

Hirlehei, A. and Hunger, A. (2011), "In designing an end-user tailorable synchronous groupware", Proceedings of 2011 International Conference on Collaboration Technologies and Systems, Philadelphia, USA, May 2327, 2011, IEEE, pp. 373-380. https://doi.org/10.1109/CTS.2011.5928713

Horváth, I. (2012), "Recent developments in computer supported cooperative work in design: From group collaboration through global connectivity to informing apobetics", Proceedings of CSCWD $2012 /$ the $16^{\text {th }}$ International Conference on Computer Supported Cooperative Work in Design, Wuhan, China, May 23-25, 2012, IEEE, pp. 2-13. https://doi.org/10.1109/CSCWD.2012.6221790

Iacob, C. (2011), "Identifying, relating, and evaluating design patterns for the design of software for synchronous collaboration", Proceedings of EICS'11 / the $3^{\text {rd }}$ ACM SIGCHI symposium on Engineering interactive computing systems, Pisa, Italy, June 13-16, 2011, ACM Press, New York, USA, p. 323-326. https://doi.org/10.1145/1996461.1996547 
Jinghua, W., Liyi, Z. and Hongxiang, X. (2014), "Simulation of project scheduling through the rule-based coordination in indirect collaboration design", Journal of Simulation, Vol. 8 No. 4, pp. 251-258. https://doi.org/10.1057/jos.2013.25

Khalil, C., Fernandez, V. and Houy, T. (2013), "Can agile collaboration practices enhance knowledge creation between cross-functional teams?", Proceedings of DED\&M 2013 / the $1^{\text {st }}$ International Conference on Digital Enterprise Design and Management, Springer, Berlin, Heidelberg, pp. 123-133. https://doi.org/10.1007/9783-642-37317-6 11

Li, Y.F., Mou, H.H. and Yu, J.G. (2011), "Establishment of CSCD in PTC Environment", Applied Mechanics and Materials, Vol. 42, pp. 200-203. https://doi.org/10.4028/www.scientific.net/AMM.42.200

Liu, W., Pasman, G., Taal-Fokker, J. and Stappers, P.J. (2014), "Exploring "Generation Y" interaction qualities at home and at work", Cognition, Technology \& Work, Vol. 16 No. 3, pp. 405-415. https://doi.org/10.1007/s10111-013-0269-4

Luck, R. (2013), “Articulating (mis)understanding across design discipline interfaces at a design team meeting”, Artificial Intelligence for Engineering Design, Analysis and Manufacturing, Vol. 27 No. 2, pp. 155-166. https://doi.org/10.1017/S089006041300005X

Mamo, J., Farrugia, P. Borg, J., Wodehouse, A., Grierson, H. and Kovacevic, A. (2015), "Using engineering design tools in multidisciplinary distributed student teams", Proceedings of the $17^{\text {th }}$ International Conference on Engineering and Product Design Education, Loughborough, UK, September 3-4, 2015, pp. 99-104.

Mattessich, P.W. and Monsey, B.R. (1992), Collaboration: what makes it work. A review of research literature on factors influencing successful collaboration, Amherst H. Wilder Foundation, St. Paul, Minnesota.

Pavković, N., Štorga, M., Bojčetić, N. and Marjanović, D. (2013), "Facilitating design communication through engineering information traceability", Artificial Intelligence for Engineering Design, Analysis and Manufacturing, Vol. 27 No. 2, pp. 105-119. https://doi.org/10.1017/S0890060413000012

Rapanta, C., Maina, M., Lotz, N. and Bacchelli, A. (2013), "Team design communication patterns in e-learning design and development", Educational Technology Research and Development, Vol. 61 No. 4, pp. 581-605. https://doi.org/10.1007/s11423-013-9306-5

Shen, W., Barthès, J.-P. and Luo, J. (2015), “Computer Supported Collaborative Design: Technologies, Systems, and Applications" In: Zhou, M. Li, H.-X. and Weijnen, M. (Eds.), Contemporary Issues in Systems Science and Engineering, John Wiley and Sons, Inc., pp. 537-573. https://doi.org/10.1002/9781119036821.ch14

van Dijk, J. and van der Lugt, R. (2013), "Scaffolds for design communication: Research through design of shared understanding in design meetings", Artificial Intelligence for Engineering Design, Analysis and Manufacturing, Vol. 27 No. 2, pp. 121-131. https://doi.org/10.1017/S0890060413000024

Vyas, D., Nijholt, A. and van der Veer, G. (2010b), "Supporting cooperative design through "living" artefacts", Proceedings of NordiCHI '10 / the $6^{\text {th }}$ Nordic Conference on Human-Computer Interaction: Extending Boundaries, Reykjavik, Iceland, October 16-20, 2010, ACM Press, New York, USA, pp. 541-550. https://doi.org/10.1145/1868914.1868975

Vyas, D., Nijholt, A., Heylen, D., Kröner, A. and van der Veer, G. (2010a), "Remarkable Objects: Supporting Collaboration in a Creative Environment", Proceedings of UbiComp '10 / the $12^{\text {th }}$ ACM International Conference on Ubiquitous Computing, Copenhagen, Denmark, September 26-29, 2010, ACM Press, New York, USA, pp. 37-40. https://doi.org/10.1145/1864349.1864357

Vyas, D., van der Veer, G. and Nijholt, A. (2013), "Creative practices in the design studio culture: collaboration and communication", Cognition, Technology \& Work, Vol. 15 No. 4, pp. 415-443. https://doi.org/10.1007/s10111-012-0232-9

Wangsa, I.T., Uden, L. and Mills, S.F. (2011), "Using Activity Theory to develop requirements analysis framework for Collaborative Working Environments", Proceedings of CSCWD $2011 /$ the $15^{\text {th }}$ International Conference on Computer Supported Cooperative Work in Design, Lausanne, Switzerland, June 8-10, 2011, IEEE, pp. 756-763. https://doi.org/10.1109/CSCWD.2011.5960203

Xie, C., Wu, D., Lou, J. and Hu, X. (2010), “A case study of multi-team communications in construction design under supply chain partnering”, Supply Chain Management: An International Journal, Vol. 15 No. 5, pp. 363370. https://doi.org/10.1108/13598541011068279

Zheng, J. and Feng, Y. (2012), "Study on the Collaborative Product Design Platform in the context of the Internet of Things", Proceedings of CECNet 2012 / the $2^{\text {nd }}$ International Conference on Consumer Electronics, Communications and Networks, Yichang, China, April 21-23, 2012, IEEE, pp. 3538-3542. https://doi.org/10.1109/CECNet.2012.6202225

Ross Brisco, PhD Student University of Strathclyde, Design, Manufacture and Engineering Management 109 Dundee Drive, G52 3HL Glasgow, United Kingdom

Email: ross.brisco@strath.ac.uk 